Research Article

\title{
Seismic Test and Simulation of Spring Vibration Isolated Foundation for Turbo-Generator
}

\author{
Dong An (i) and Tianwang Liu \\ School of Civil Engineering, North China University of Technology, Beijing 100144, China \\ Correspondence should be addressed to Dong An; hadesloveln@163.com
}

Received 14 July 2020; Revised 15 December 2020; Accepted 20 February 2021; Published 3 March 2021

Academic Editor: Dr Vasant Matsagar

Copyright (C) 2021 Dong An and Tianwang Liu. This is an open access article distributed under the Creative Commons Attribution License, which permits unrestricted use, distribution, and reproduction in any medium, provided the original work is properly cited.

\begin{abstract}
The 1:8 model of turbo-generator vibration isolated foundation of common islands in nuclear plants was established for vibration characteristic tests and pseudodynamic experiments. The finite element model was established by SeismoStruct for time-history analysis. Frequencies, modal shapes and seismic responses, deformation curves, and spring deformations were compared and analyzed. Results from tests and experiments show that the natural frequencies of spring vibration isolation foundation are lower than those of common frame foundations and the vertical frequencies are far from the working disturbance frequency of the turbo-generator units. The spring vibration isolation device can reduce the acceleration response of the TG (turbo-generator) deck and redistribute the horizontal earthquake action of the foundation according to the stiffness to give full play to the seismic capacity of the columns. The errors of natural vibration frequencies and maximum seismic response are approximately $15 \%$ and $10 \%$, respectively, and the simulation results are in good agreement with the test and experiment data. The proportion and distribution of spring deformation are close, and the test study shows the convenient and precise realization of the simulation. Results of seismic experiments and numerical simulations show that the foundation design meets the standard of the "Code for Seismic Design of Buildings" in China, which realizes the goal of spring vibration isolation and seismic resistance. The foundation design is also reasonable, safe, and reliable.
\end{abstract}

\section{Introduction}

The statistics [1] reveal that more than 40 nuclear power units in mainland China have entered commercial operation, approximately 20 units are under construction, and additional units are ready to be built or are being planned. Figure 1 shows the distribution of nuclear power plants in mainland China. Turbo-generator (TG) is the "heart" of power plants and even power systems. TG is the core component either in thermal power or nuclear power. As the structure of nuclear power conventional island carrying the entire TG unit, the turbine foundation not only bears huge equipment weight but also handles the dynamic load of the turbine. Figure 2 is a typical conventional turbine foundation [2]. The use of a half-speed TG will inevitably increase with the development of nuclear power design autonomy and large-scale unit power. However, its $25 \mathrm{~Hz}$ operating frequency is close to the vertical basic frequency of common frame foundation, which is prone to produce the "resonance" effect that is not conducive to unit operation.

Spring isolation technology was first applied to TG more than 50 years ago. Researchers [3] found there are two strategies to reduce the seismic response of turbine foundations: one is to reduce the fundamental frequency of the structure, and the other is to improve the damping of the system. The spring vibration isolation system, which separates the TG deck and the column, can satisfy the two aforementioned points. This system not only substantially reduces the vertical natural frequency but also adjusts the damping of the entire system appropriately. Although many engineering examples of spring vibration isolation foundation are found abroad, no real systematic theoretical or experimental study, which is limited to the actual measurement of TG on the working state [4], is unavailable. However, the use of spring vibration isolation foundation in conventional nuclear power island has no precedent at that 


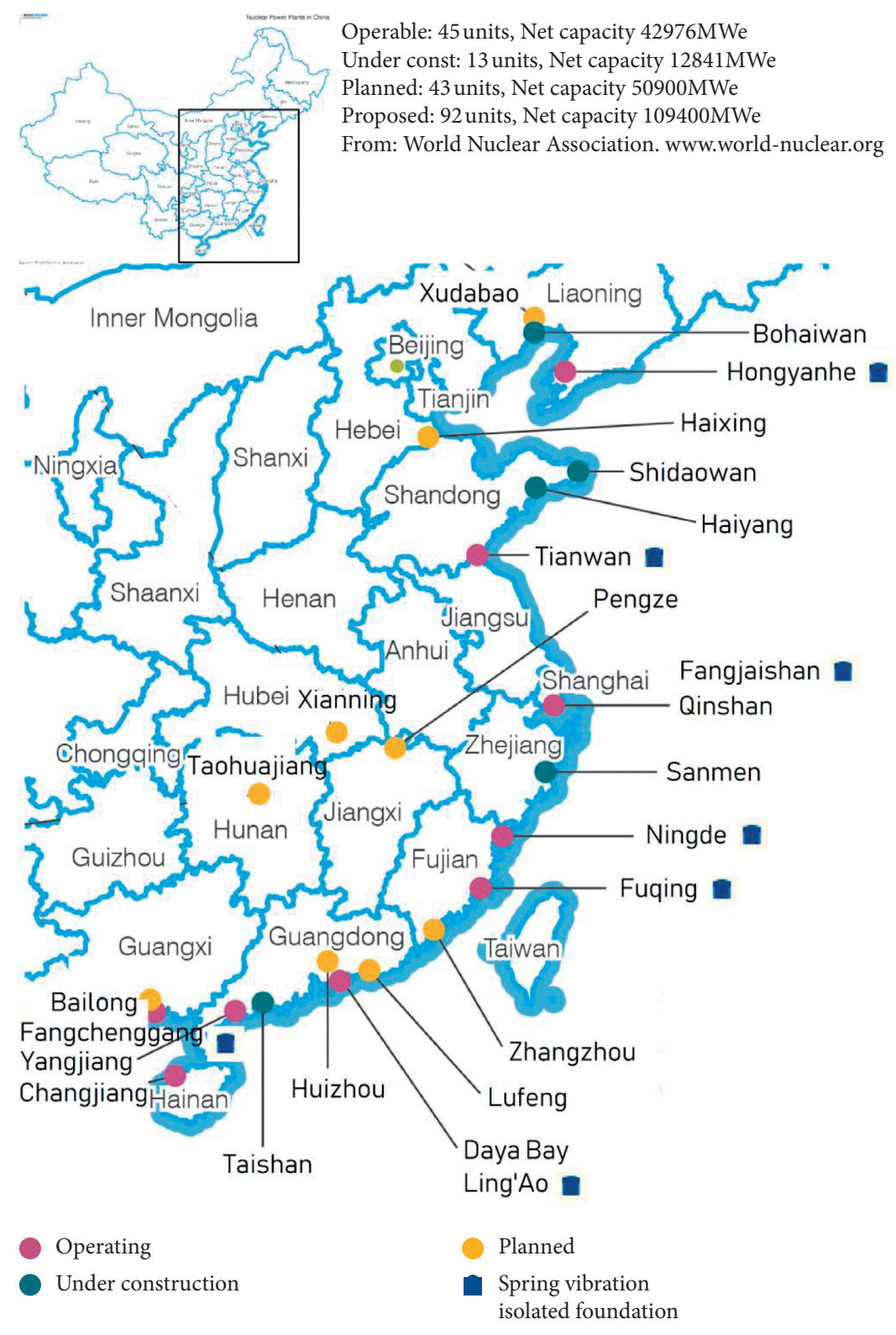

FIgURE 1: Nuclear power plants in China.

time in China. Thus, effectively executing design selection, theoretical analysis, experimental research, and field testing is necessary. Chinese experts and scholars conducted numerous studies. Luo et al. [3] discussed the seismic performance of three examples using the spring vibration isolation foundation and obtained similar conclusions despite differences in the foundation model, calculation program, calculation assumption, and calculation method. Spring vibration isolation foundation can also reduce the basic frequency of turbine foundations, and the use of dampers to improve the damping ratio of the system can effectively reduce the seismic responses. Zhu and Chen [5] established the dynamic equation of the spring vibration isolation system and conducted the finite element analysis. The results reveal that the spring vibration isolation damping element can advance the basic frequency of the entire structure system and reduce the probability of resonance under the working frequency. Song et al.[6] conducted a series of studies on the foundation selection, design criteria, vibration analysis, and field test of the first Ling'Ao Phase II half-speed machine with spring vibration isolation foundation in China. The results show that the vertical first-order frequency of the spring foundation is far less than the working frequency of the half-speed unit which has effective dynamic characteristics. The acceleration response of the TG deck can be reduced by spring vibration isolation, and the foundation has a good seismic performance. The application of spring vibration isolation foundation in conventional nuclear power island has been successful. The experimental research is a necessary verification and an important supplement for theoretical analysis and field measurement. Shao et al. $[4,7]$ conducted the first comprehensive model test on 


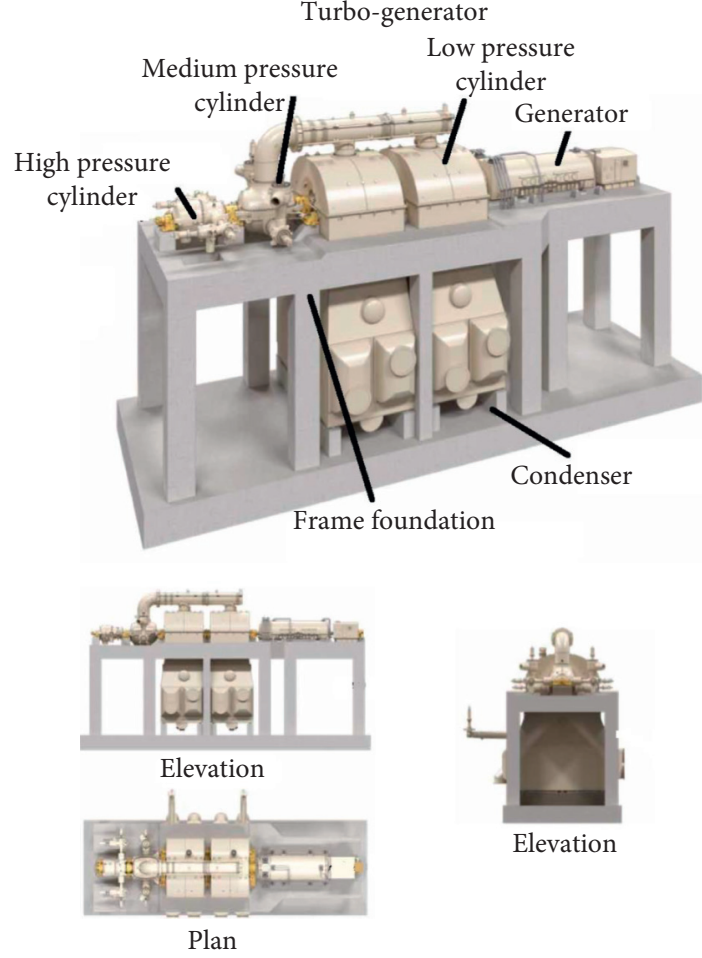

FIGURE 2: Concrete foundations for turbine generators (HP-IP-LPLP with bottom exhaust).

spring vibration isolation foundations of TG unit. The test results show that the spring vibration isolation improves the seismic performance of the foundation, and the increase in the damping ratio is beneficial to the improvement of the seismic performance. Considering dynamic characteristics, the overall calculation model is close to the test results. The spring vibration isolation foundation is the best choice for a half-speed TG with a working frequency of $25 \mathrm{~Hz}$. Researchers tended to provide additional attention to the influence of dynamic characteristics of turbine foundation on TG deck vibration and performed numerous investigations have done a considering common or spring foundation [8-12]. With the application of spring isolation technology and additional advanced research methods, Li et al.[12] built a TG deck and spring isolation foundation combined vibration test bench. Particularly, the influence of spring isolation foundation on TG deck vibration is investigated. A $300 \mathrm{MW}$ turbine-generator-foundation system is analyzed under earthquakes [13]. A new seismic isolation system based on spring tube braces was studied [14]. Hur and Park [15] evaluated the applicability of seismic isolation devices under seismic loads.

The TG foundation has the following characteristics. (1) Installed capacity and number of cylinders affect the TG deck condition of the unit. Thus, selecting the foundation and allocating the unit to meet the dynamic characteristics of the TG deck operation are necessary. (2) Technological requirements of different manufacturers lead to different shapes of the foundation structure or different parts of the location. (3) The structure of the foundation is complex, the weight of the upper structure and equipment is huge, and the size of the TG deck beam is large. Meanwhile, the space occupied by the lower condenser is large. However, the size of the column is relatively small. The difference of foundations in the TG foundation model experiments [4, 16-20] is considerably large. Therefore, examining the difference separately is necessary. Especially for spring vibration isolation foundation, the overall dynamic characteristics of the foundation will change markedly when the spring vibration isolator is placed at the top of the column. The Code for Seismic Design of Buildings (2016) [21] stipulates that "when a complex structure adopts vibration isolation design, the design scheme shall be determined after model test."

The seismic performance of spring vibration isolation foundations of TG units is studied in this paper through physical modelling and numerical simulation. First, the $1: 8$ spring vibration isolation foundation model of the TG unit is designed and manufactured following similarity theory. The basic frequency and mode shape of the foundation are obtained by the natural characteristic test. Then, the current codes in China and the requirements of manufacturers indicate that the acceleration time history of 7-degree fortification earthquake is input, and the seismic performance under the horizontal earthquake action of the foundation is studied by pseudodynamic experiments. Simultaneously, the finite element software SeismoStruct is used to simulate the spring foundation, and the simulation results are compared with the experimental results. Finally, the evaluation of the seismic performance of the foundation and the suggestions of similar tests are given to guide for the design and test loading of this kind of structure.

\section{Experimental Investigation}

2.1. Model Design and Fabrication. Adopting the frame structure, the scale ratio of the turbine spring vibration isolation foundation model is $1: 8$. The plan and section of the model are shown in Figure 3, the dimensions indicated in the figure are in millimeters, and the model similarity [22] is presented in Table 1. The model material is similar to the prototype of the practical project. The longitudinal reinforcement of the beam, column, and slab is HRB400, the stirrup is HPB300, and the concrete strength grade is C40. The abovementioned grades are Chinese code values. The reinforcement ratio of the foundation model is similar to that of the prototype. The principle of quality similarity indicates that the quality of equipment used in TGs is simulated by cast iron block, and the position of the mass block is consistent with that of equipment. The concrete base plate is anchored to the laboratory floor by foot bolts. The concrete construction of the whole foundation structure is divided into five parts. The five parts are as follows: the base plate, the column and one-story platform, the column and two-story platform, the upper part of the column, and the TG deck. The spring vibration isolation device is installed after the upper part of the column has been constructed. The completed model used in natural characteristic tests and seismic experiments is shown in Figure 4. The stiffness of 

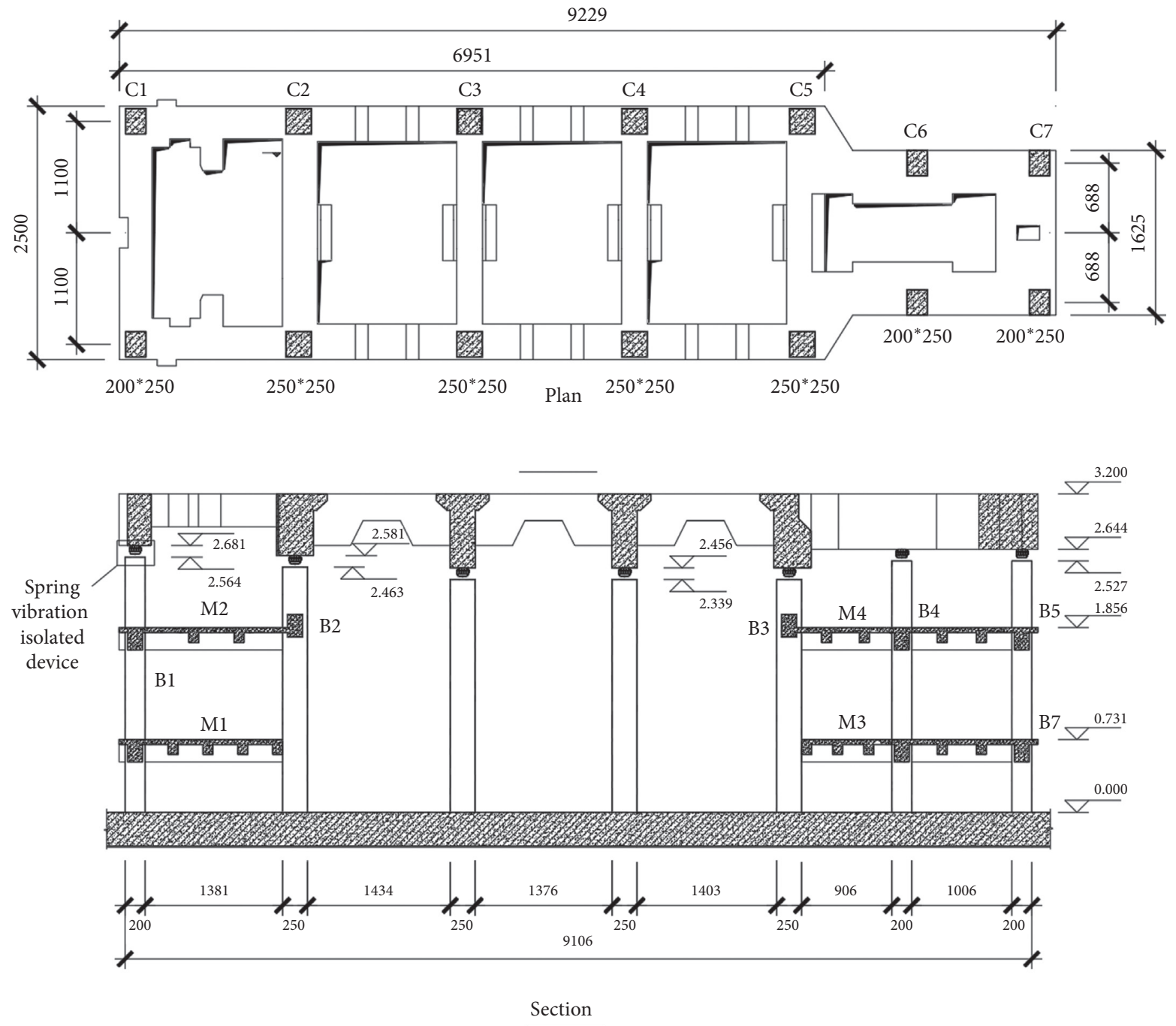

FIgURE 3: Layout drawing of test model (mm).

TABLE 1: Similarity relation of scale model.

\begin{tabular}{lc}
\hline Length & Coefficient \\
\hline Geometry size & $1: 8$ \\
Modulus of elasticity & $1: 1$ \\
Density & $1: 1$ \\
Force (gravity, horizontal resistance) & $1: 8$ \\
Stiffness & $1: 8$ \\
Mass & $1: 512$ \\
Time (period) & $1: 8$ \\
Frequency & $8: 1$ \\
Acceleration & $8: 1$ \\
Displacement & $1: 8$ \\
\hline
\end{tabular}

each spring isolated device installed in the model is shown in Table 2.

\subsection{Natural Vibration Characteristic Test}

2.2.1. Instrumentation. The dynamic signal analyzer, data acquisition, and modal analysis software used in the self-

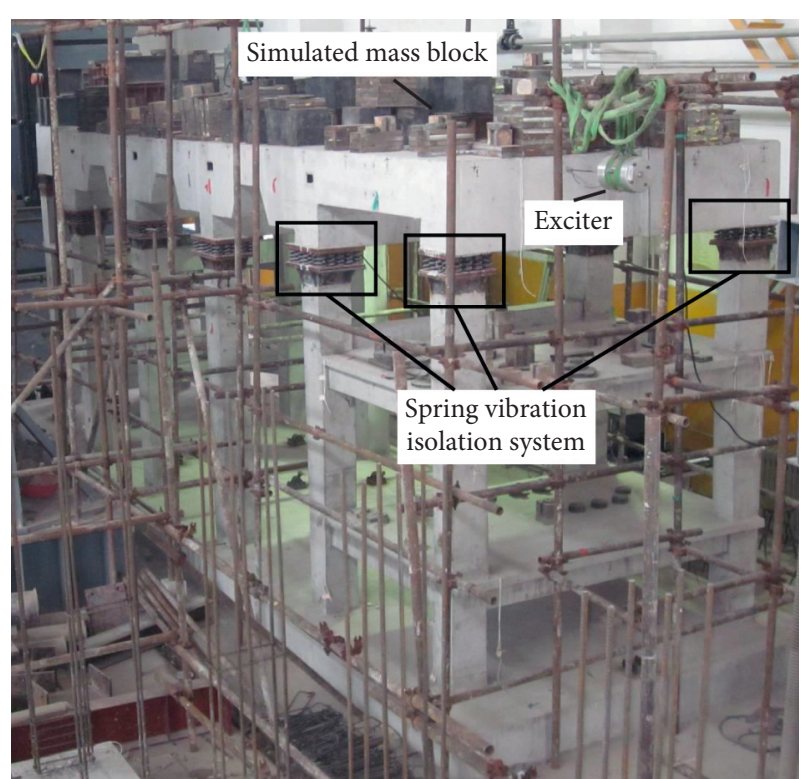

Figure 4: Photo of the experimental model. 
TABLE 2: Stiffness of spring isolated device $(\mathrm{kN} / \mathrm{mm})$.

\begin{tabular}{lcccccc}
\hline Column number & & C1 & C2 & C3/C4/C5 & C6 & C7 \\
\hline \multirow{2}{*}{ Spring stiffness } & Vertical & 30.96 & 59.09 & 52.44 & 36.34 & 20.89 \\
& Horizontal & 16.01 & 29.74 & 25.44 & 20.24 & 11.36 \\
\hline
\end{tabular}

vibration characteristic test are all from Belgium LMS International Company. Acceleration and force transducers were obtained from PCB Company in the United States.

2.2.2. Test Method. The multipoint spatial excitation multipoint three-dimensional measurement method was used to test the self-vibration characteristics of the model. Three excitation points were selected as horizontal transverse ( $X$ direction), horizontal longitudinal ( $Y$ direction), and vertical ( $Z$ direction) excitation points to exert excitation force on the model, and the responses of several measurement points selected in accordance with the characteristics of the model in three directions were measured. One of the exciters, which has a horizontal longitudinal direction ( $Y$ direction), is shown in Figure 4.

2.2.3. Layout of Measuring Points. Under the condition that the excitation energy is distributed throughout the foundation, the measurement points are arranged, and the excitation measurement model is established. Figure 5 shows that the excitation points of nos. 30, 3, and 15 are $X, Y$, and $Z$ directions, respectively.

\subsection{Pseudodynamic Test}

2.3.1. Test Setup. Pseudodynamic test is suitable for largescale model tests. Actuators are used to exert effects on the model. Therefore, the influence of the applied effect is similar to that of the real earthquake. Turbine generator with its foundation can be modeled as a single degree of freedom (SDOF) [23]. Single point loading is adopted in this paper. The natural frequencies of the two horizontal principal axes of the spring isolation foundation studied in this paper are remarkably close. Exerting seismic action on the spring isolation foundation in two directions is necessary; that is, the seismic test is divided into longitudinal and horizontal directions.

2.3.2. Loading System. Pseudodynamic test is a computeractuator online test. The rated load of the horizontal hydraulic servo actuator used in this paper is $500 \mathrm{kN}$ and the stroke is $250 \mathrm{~mm}$. Gravity effect is generally neglected in conventional dynamic characteristic tests. However, in the pseudodynamic test of spring vibration isolation foundation, the gravity effect will influence the vertical deformation of spring. Therefore, a vertical preloading hydraulic system is added to the pseudodynamic test device in this paper to simulate the gravity effect. The test loading device and field are shown in Figures 6 and 7.
2.3.3. Measurement Scheme. Linear variable differential displacement transducers are arranged on the intermediate platform (one and two stories), column top, and beam and column joints of the intermediate platform to measure the displacement of the model in real-time during the pseudodynamic test. The displacement sensor number is shown in Figure 3.

2.3.4. Selection of Seismic Waves. The fortification intensity of the project is 7 degree of China code, the basic design acceleration is $0.1 \mathrm{~g}$, and the earthquake is divided into the first group and the site category II. First, two typical strong earthquake records were selected following the requirements of the manufacturer, namely, Imperial Valley (USA, 1979) and Alaska (USA, 2002). Then, the code response spectrum was used as the target spectrum, and an artificial seismic wave was generated iteratively. Each seismic wave was loaded in two directions. The digital seismic acceleration time history was adjusted in accordance with the fortification intensity, and its peak value is adjusted to $0.1 \mathrm{~g}$, which is the basic acceleration of 7-degree fortification earthquake. The seismic wave and its response spectrum used in the pseudodynamic test are, respectively, shown in Figures 8 and 9. According to the different directions of the input seismic wave, the pseudodynamic test can be divided into six working conditions, as shown in Table 3.

2.3.5. Parameters. Table 4 lists the test parameters used in the pseudodynamic test.

\section{Finite Element Analysis}

SeismoStruct is used in this study to simulate the seismic response of foundation model structures. The program can consider geometric and material nonlinearities to conduct structural time-history and IDA analyses.

3.1. Material Model and Element Type. The material parameters of concrete and steel bar used in the numerical simulation agree with those of the test. Reinforced Menegotto-Pinto model [24] is adopted for the constitutive relationship of steel bars, which is suitable for repeated loading. The concrete adopts the nonlinear constitutive model of concrete [25]. The section of beam and column is simplified following the test drawings and individual positions. The section can define the diameter, position, and number of longitudinal reinforcement and stirrups. InfrmDB element based on displacement is used in the beam-column element. The number of the cross-section fibers is 150 , and the shape of cross-section is slightly different. Rayleigh damping is adopted, and the damping ratio is 0.05 . The link element is used to simulate the spring vibration isolation device, and a linear model is used. The horizontal and vertical stiffness are consistent with the spring vibration isolation device used in the experimental model. Additional mass is consistent with the position and size of cast iron mass block in the test. According to the 


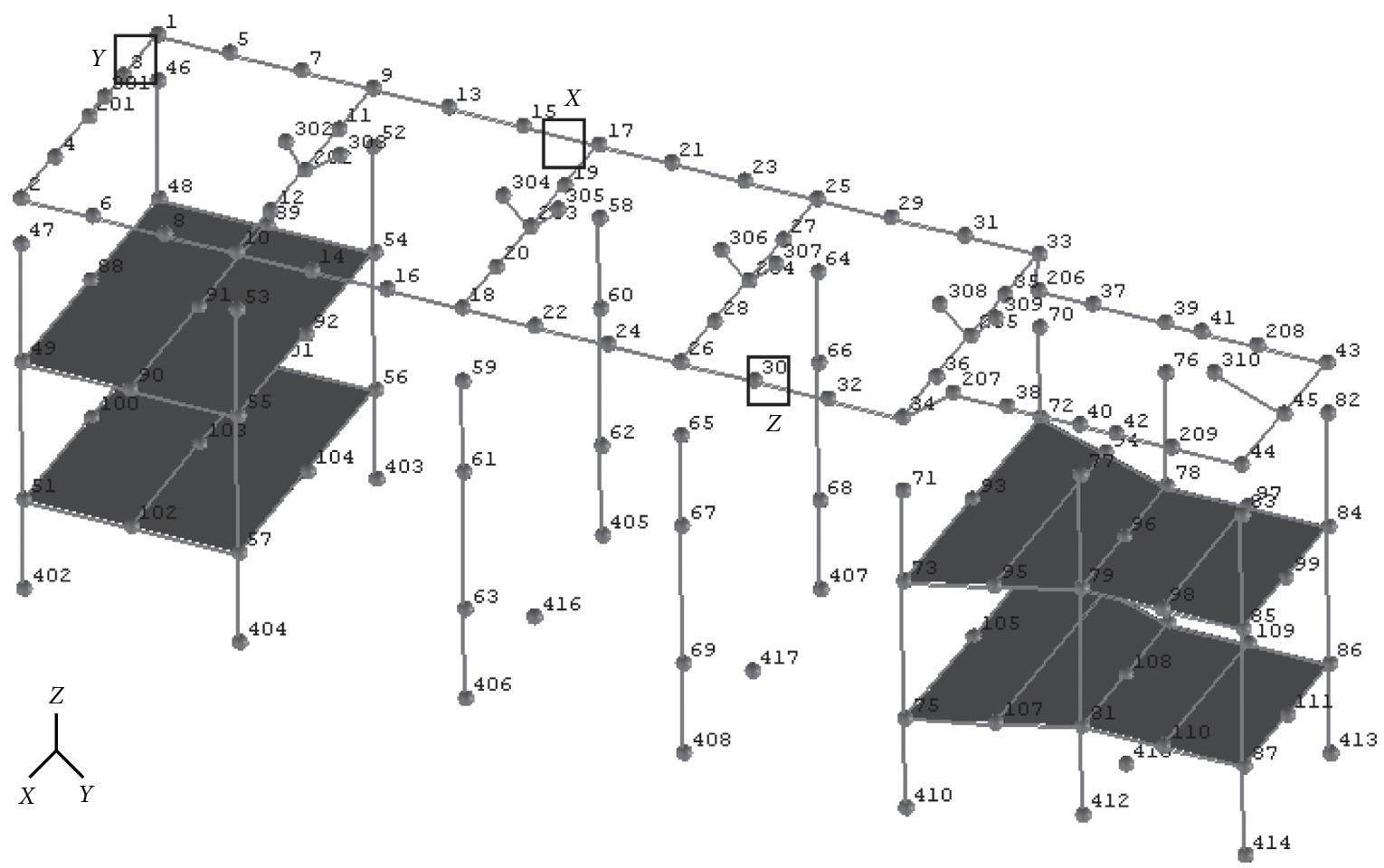

FIGURE 5: Distribution of measuring points for self-vibration test.

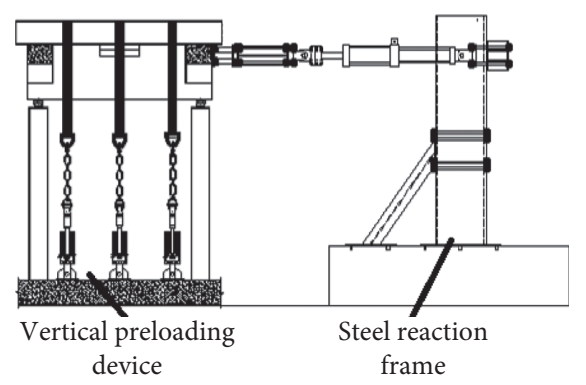

(a)

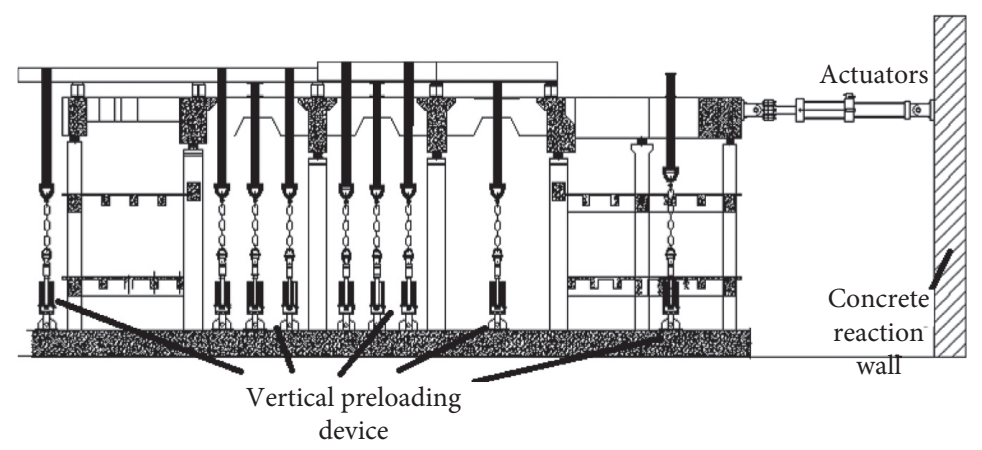

(b)

FIGURE 6: Loading system for pseudodynamic experiment. (a) Transverse loading. (b) Longitudinal loading.

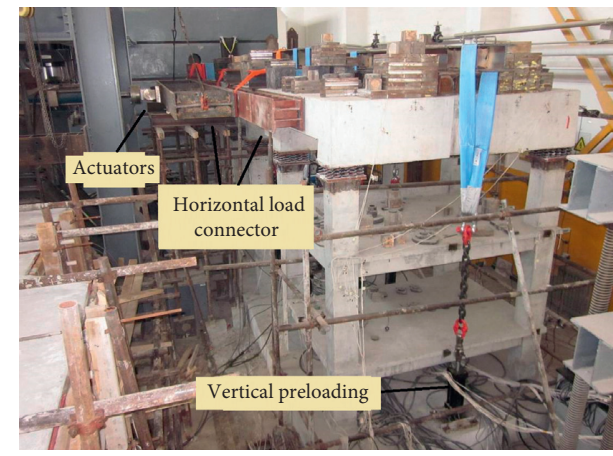

(a)

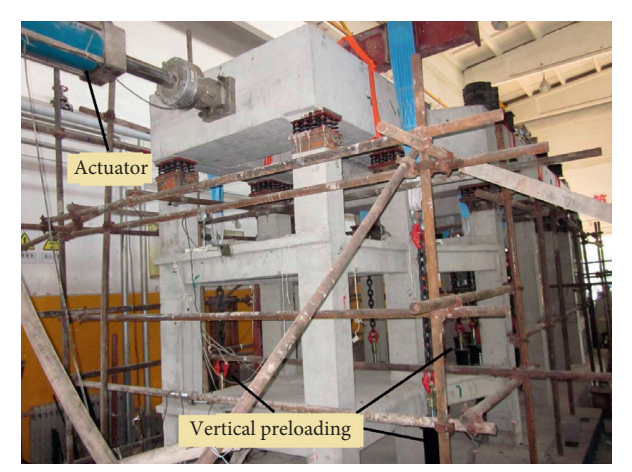

(b)

Figure 7: Photo of pseudodynamic experiment. (a) Transverse loading. (b) Longitudinal loading. 


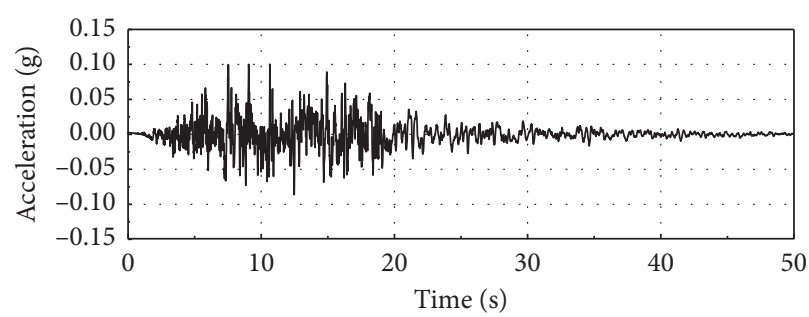

(a)

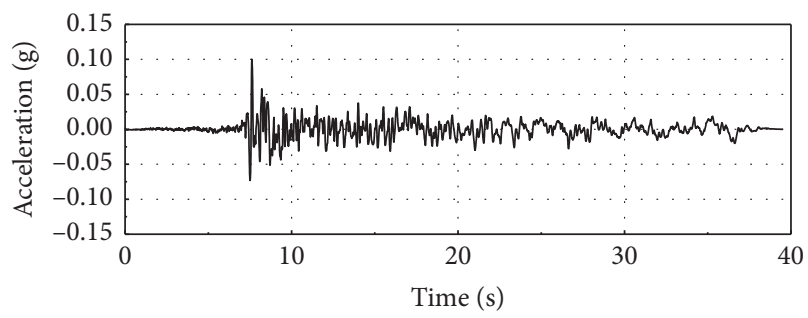

(c)

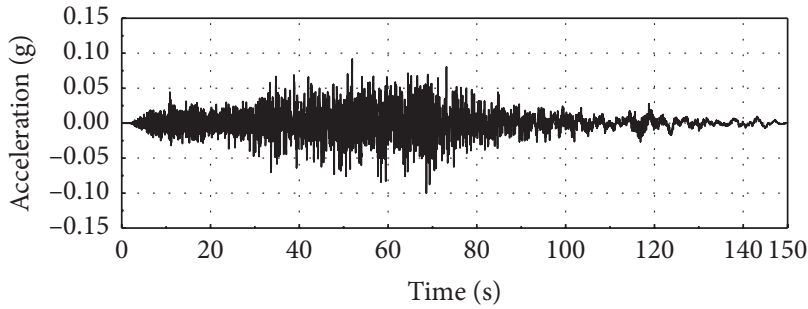

(e)

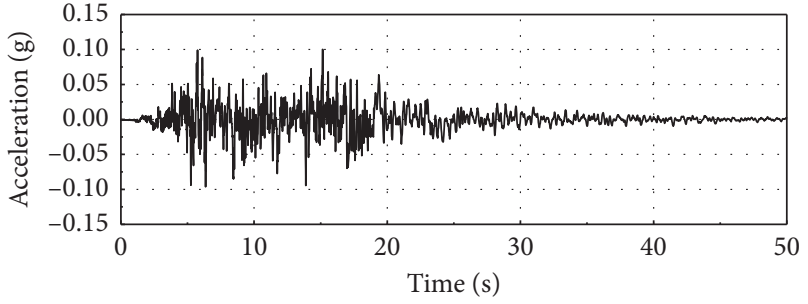

(b)

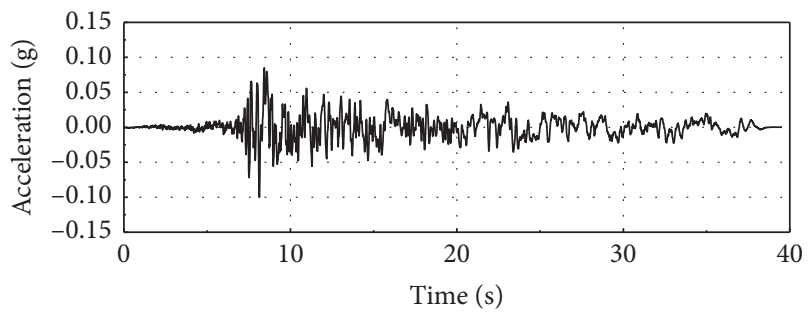

(d)

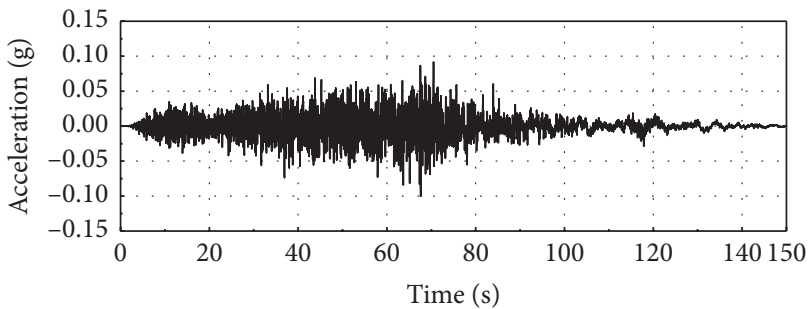

(f)

FIGURE 8: Earthquake acceleration time-history curves of intensity 7 fortification. (a) Synthesized (transverse input). (b) Synthesized (longitudinal input). (c) Imperial Valley (transverse input). (d) Imperial Valley (longitudinal input). (e) Alaska (transverse input). (f) Alaska (longitudinal input).

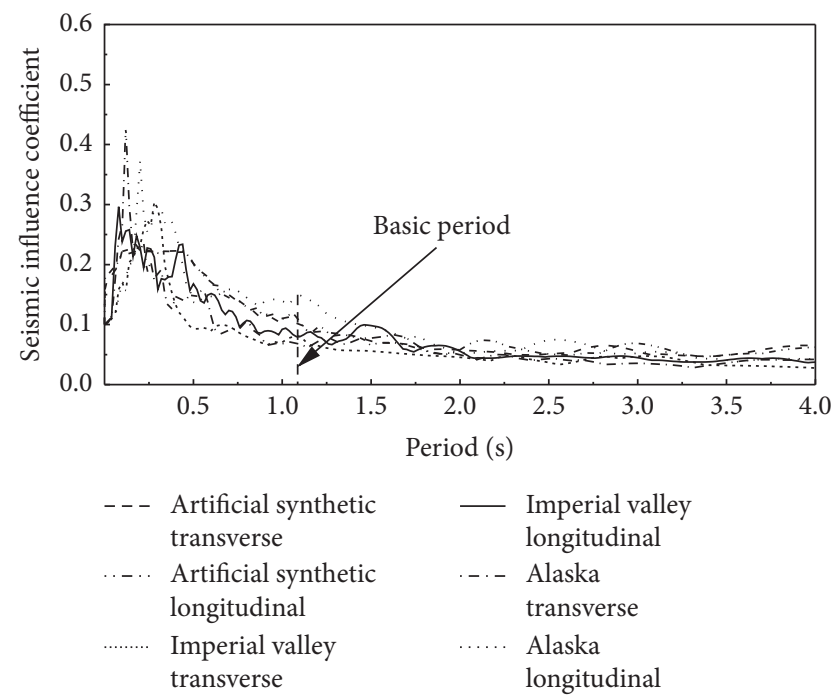

FIGURE 9: Response spectra of acceleration applied in pseudodynamic experiments.

above selection, the SeismoStruct model of the TG spring foundation in this paper is shown in Figure 10. The figure reveals the division and approximate size of beam-column section elements. Green squares, blue squares, gray squares,
TABle 3: Experimental conditions (7-degree fortification).

\begin{tabular}{lcc}
\hline Earthquake type & Direction & Number \\
\hline \multirow{2}{*}{ Artificial synthetic } & Transverse & Condition 1 \\
& Longitudinal & Condition 2 \\
\hline \multirow{2}{*}{ Imperial Valley } & Transverse & Condition 3 \\
& Longitudinal & Condition 4 \\
\hline \multirow{2}{*}{ Alaska } & Transverse & Condition 5 \\
& Longitudinal & Condition 6 \\
\hline
\end{tabular}

TABLE 4: Experiment parameters.

\begin{tabular}{|c|c|c|}
\hline Parameter & & Value \\
\hline Time step (s) & & 0.00125 \\
\hline Loading speed (s) & & 10.0 \\
\hline Equivalent mass (kg) & & 26728 \\
\hline Vertical preload $(\mathrm{kN})$ & & 1680 \\
\hline Damping ratio $(/)$ & & 0.05 \\
\hline Initial stiffness $\left(10^{3} \mathrm{kN} / \mathrm{m}\right)$ & $\begin{array}{l}\text { Transverse } \\
\text { Longitudinal }\end{array}$ & $\begin{array}{l}48.4 \\
50.0\end{array}$ \\
\hline
\end{tabular}

and green arrows, respectively, denote additional mass, spring elements, column bottom consolidation, and the location and direction of ground motion input (taking longitudinal as an example). 


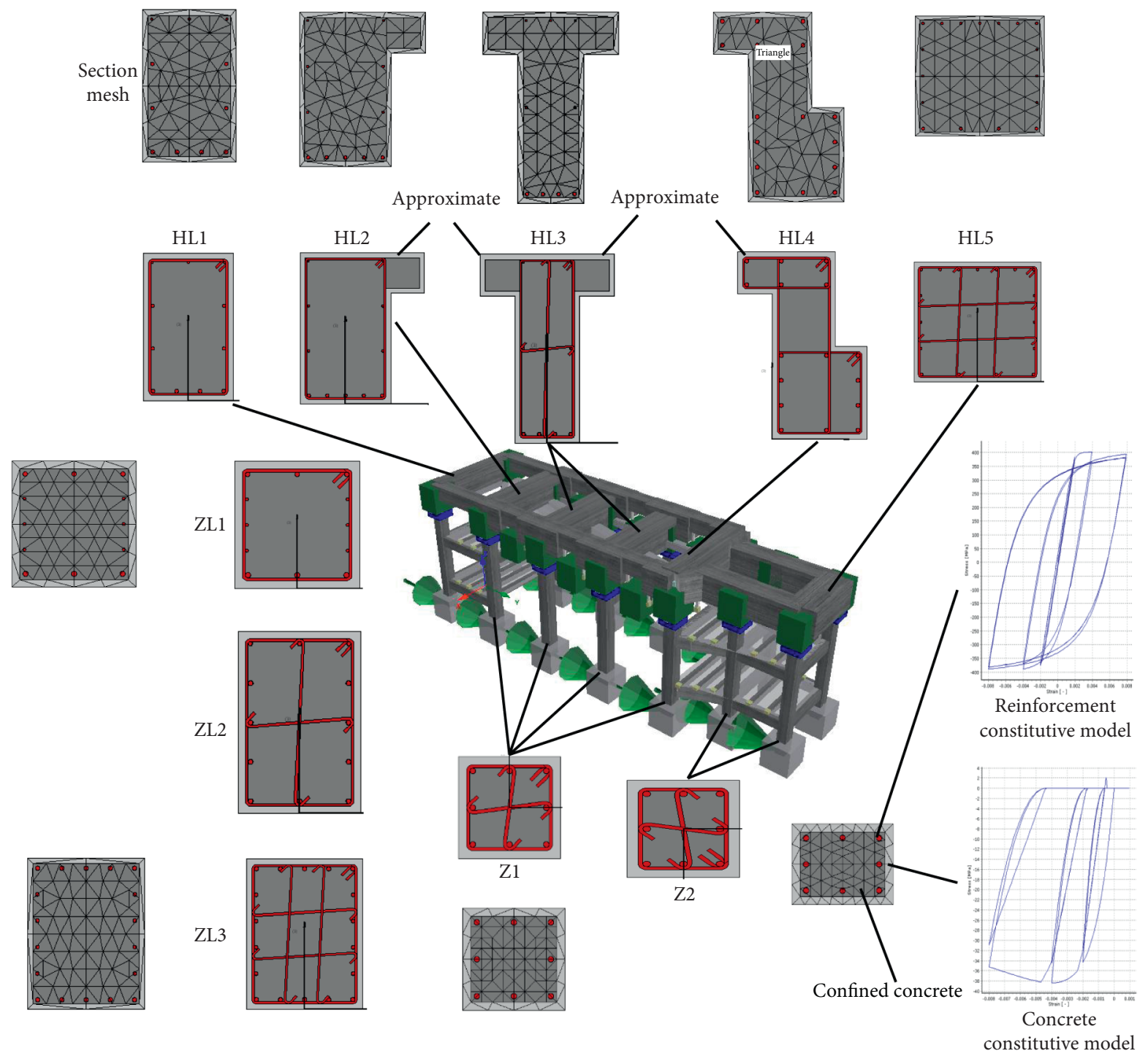

Figure 10: Model established by SeismoStruct and section mesh.

3.2. Ground Motion Input. In the pseudodynamic test, the foundation model is approximated as an equivalent single degree of freedom system because the equipment weight is concentrated on the TG deck, and the actuator acts on the elevation of the TG deck. SeismoStruct numerical simulation does not need to make this approximation. The input position of earthquake motion is directly at the bottom of the column.

\section{Results}

\subsection{Natural Vibration Characteristics}

4.1.1. Natural Frequency. The frequency results obtained from the natural vibration test are converted to the prototype according to the similarity ratio. This paper mainly compares the results of the modal test and numerical simulation. Two methods are used for numerical simulation: one is the SeismoStruct model, and the other is the
STARDYNE program adopted by the manufacturer, which uses the bar element. Among these methods, the calculation model of STARDYNE is divided into the top deck model (without considering the structure below the vibration isolation device) and overall model (TG deck and substructure considering the column and the intermediate platform). Table 5 compares the natural frequencies of the experimental and numerical results. The first six frequencies and modal shapes reveal that the test results are in good agreement with that of numerical simulation, and the error is small, which shows that the numerical simulation is reasonable. In the first six orders, the results of the low-order model test are smaller than those of the numerical simulation, while the results of the high-order model test are large. This result indicates that the numerical simulation regards the end of the column as consolidation, which improves the stiffness of the entire structure, thereby resulting in the vibration of the TG deck. Moreover, the results of numerical simulation are large and involve the 
TABLE 5: Contrast of natural frequencies $(\mathrm{Hz})$.

\begin{tabular}{|c|c|c|c|c|c|}
\hline \multirow{3}{*}{ Mode shape characteristics } & & \multirow{3}{*}{ Test } & \multicolumn{3}{|c|}{ Numerical simulation } \\
\hline & & & \multirow{2}{*}{ SeismoStruct } & \multicolumn{2}{|c|}{ STARDYNE } \\
\hline & & & & Top deck & TG deck and substructure \\
\hline Transverse translation & & 0.92 & $1.06(15 \%)$ & $1.06(15 \%)$ & $1.04(13 \%)$ \\
\hline Longitudinal translation & & 1.01 & $1.15(14 \%)$ & $1.12(11 \%)$ & $1.09(8 \%)$ \\
\hline Translation torsion & & 1.23 & $1.34(9 \%)$ & $1.37(11 \%)$ & $1.34(9 \%)$ \\
\hline Vertical bending & & 3.48 & $3.26(-6 \%)$ & $3.26(-6 \%)$ & $3.25(-7 \%)$ \\
\hline \multirow{2}{*}{ Vertical swing } & Transverse & 3.57 & $2.77(-22 \%)$ & $3.04(-15 \%)$ & $3.04(-15 \%)$ \\
\hline & Longitudinal & 1 & $3.07(\backslash)$ & $4.34(\backslash)$ & $4.47(\backslash)$ \\
\hline
\end{tabular}

Note. In parentheses, the percentage of deviation between numerical model and test results is given.

vibration of the column, and the results of numerical simulation are smaller. Overall, the STARDYNE model is closest to the experimental results. The results show that the natural frequencies of spring vibration isolation foundation are low, and the vertical natural frequencies are far away from the unit operating disturbance frequency $(25 \mathrm{~Hz})$.

4.1.2. Mode Shape. Figure 11 is the modal shape diagram of the model. The test results are listed on the left, the overall model results of STARDYNE are listed in the middle, and the results of the SeismoStruct model are listed on the right (no additional mass and spring elements are shown). The first six vibration modes of the model are the entire vibration of the platform plate, which shows that the spring vibration isolation device can separate the foundation platform plate from the column and achieve a certain degree of dynamic decoupling. Thus, the dynamic transmission from the platform plate to the column can be reduced during the operation of the unit.

\subsection{Seismic Test}

4.2.1. Seismic Response. Seismic responses obtained from pseudodynamic experiments applied to the foundation are transformed into prototype results according to the similarity ratio of the model and prototype. Table 6 lists the maximum values and comparisons between the experiment and the simulation results of the foundation seismic response under various conditions. SeismoStruct is used to simulate the seismic response, and the error of the test results is approximately $10 \%$. Combining with the discussion of 3.1.1 natural frequency, the stiffness of the model established by numerical simulation is larger than that of the experimental model, especially the connection between spring vibration isolation device and column and top deck. From the viewpoint of restoring force and displacement, the simulation results are approximately 15\% larger than the experimental results, which is consistent with the analysis of self-vibration characteristics.

The requirements of the seismic code indicate that the structural joint between the foundation slab and the plant structure shall be taken as 1.2 times of the maximum displacement of the TG deck, which shall not be less than $200 \mathrm{~mm}$. The test results show that 1.2 times of the maximum displacement of the foundation slab is less than
$200 \mathrm{~mm}$. Thus, increasing the structural joint here is unnecessary.

The magnification factor of foundation (maximum response acceleration divides maximum input acceleration) is only 0.91 when 7-degree fortification earthquake is the input. This factor appearing in working condition 5 is small in other working conditions. The horizontal stiffness of the spring vibration isolation foundation is substantially lower than that of the rigid common foundation. The first-order natural frequency test value is $0.92 \mathrm{~Hz}$ (period $1.09 \mathrm{~s})$, the calculated value is $1.04 \mathrm{~Hz}$ (period $0.96 \mathrm{~s}$ ), and the predominant period is $0.35 \mathrm{~s}$ away from the site. This finding shows that the spring vibration isolation device prolongs the natural vibration period of the foundation, and the seismic influence coefficient (amplification coefficient) enters the less valuable part of the response spectrum. Spring vibration isolation devices elevate the seismic performance of the foundation.

4.2.2. Seismic Force Response. Figure 12 shows the force seismic response time history under each condition.

4.2.3. Seismic Displacement Response. Figure 13 shows a comparison of the displacement seismic response between the test and the simulation under each condition. The trend of the time-history curves of the two methods is identical and the size is close. In case 1, the test is almost the same as the first $20 \mathrm{~s}$ of the simulation, and the test curve deviates after $20 \mathrm{~s}$. Moreover, residual after the test is still observed, which indicates the presence of gap between the foundation and the transverse loading device. Follow-up experiments corrected this problem, and no similar situation occurs again. The trend and size of displacement time-history curve in the three conditions of transverse loading are relatively consistent. This finding shows that the numerical simulation is correct and can simulate the displacement response and deformation of the foundation. When the curve is loaded longitudinally, the results of simulation are larger than those of experiments, such as $10-20 \mathrm{~s}$ in condition $2,10-15 \mathrm{~s}$ in condition 4, and $50-55 \mathrm{~s}$ and $80-90 \mathrm{~s}$ in condition 6 .

4.2.4. Deformation Analysis. Figure 14 shows the maximum response of seismic displacement at different locations of the foundation under experiment condition and numerical 


\begin{tabular}{|l|c|c|c|c|c|c|}
\hline $\begin{array}{l}\text { Mode } \\
\text { hape }\end{array}$ & $\begin{array}{c}\text { Transverse } \\
\text { translation }\end{array}$ & $\begin{array}{c}\text { Longitudinal } \\
\text { translation }\end{array}$ & $\begin{array}{c}\text { Translation } \\
\text { torsion }\end{array}$ & $\begin{array}{c}\text { Vertical } \\
\text { bending }\end{array}$ & $\begin{array}{c}\text { Vertical swing- } \\
\text { transverse }\end{array}$ & $\begin{array}{c}\text { Vertical swing- } \\
\text { longitudinal }\end{array}$ \\
\hline & & & & & & \\
\hline
\end{tabular}

Figure 11: Modal shape contrast of test and simulation.

TABle 6: Max values of seismic response.

\begin{tabular}{|c|c|c|c|c|c|c|c|c|}
\hline & \multicolumn{4}{|c|}{ Seismic experiments } & \multicolumn{4}{|c|}{ SeismoStruct simulation } \\
\hline & $\begin{array}{l}\text { Displacement } \\
(\mathrm{mm})\end{array}$ & $\begin{array}{l}\text { Acceleration } \\
\left(\mathrm{m} / \mathrm{s}^{2}\right)\end{array}$ & $\begin{array}{l}\text { Velocity } \\
(\mathrm{m} / \mathrm{s})\end{array}$ & $\begin{array}{l}\text { Restoring force } \\
(\mathrm{kN})\end{array}$ & $\begin{array}{l}\text { Displacement } \\
(\mathrm{mm})\end{array}$ & $\begin{array}{l}\text { Acceleration } \\
\left(\mathrm{m} / \mathrm{s}^{2}\right)\end{array}$ & $\begin{array}{l}\text { Velocity } \\
(\mathrm{m} / \mathrm{s})\end{array}$ & $\begin{array}{l}\text { Restoring force } \\
\qquad(\mathrm{kN})\end{array}$ \\
\hline 1 & 37.17 & 0.64 & 0.13 & 8484 & $32.55(12 \%)$ & $0.60(6 \%)$ & $0.12(8 \%)$ & $9948(-17 \%)$ \\
\hline 2 & 32.60 & 0.69 & 0.14 & 9485 & $35.78(-10 \%)$ & $0.77(-12 \%)$ & $0.17(-21 \%)$ & $9636(-2 \%)$ \\
\hline 3 & 25.99 & 0.52 & 0.11 & 7081 & $24.67(5 \%)$ & $0.45(13 \%)$ & $0.10(9 \%)$ & $7727(-9 \%)$ \\
\hline 4 & 47.43 & 0.91 & 0.19 & 12367 & $48.59(-2 \%)$ & $0.93(-2 \%)$ & $0.21(-11 \%)$ & $14444(-17 \%)$ \\
\hline 5 & 41.77 & 0.73 & 0.16 & 9734 & $37.25(11 \%)$ & $0.59(19 \%)$ & $0.13(19 \%)$ & $9585(2 \%)$ \\
\hline 6 & 39.14 & 0.75 & 0.16 & 10266 & $37.84(3 \%)$ & $0.85(-13 \%)$ & $0.18(-13 \%)$ & $12888(-26 \%)$ \\
\hline
\end{tabular}

Note. In parentheses, the percentage of deviation between test and simulation results is shown. The positive value indicates that the test results are larger than the simulation results.

simulation. The measurement points of displacement are arranged from bottom to top on each column, two intermedium platforms, column tops and top deck. The section of $\mathrm{C} 2$ column and M1/M2 platform is taken as an example for transverse loading, while C7 column and M3/M4 platform are taken as examples for longitudinal loading. Among these examples, B6 and B7 are the measuring points of one-story platform beam, B2 and B5 are the measuring points of twostory platform beam, B2 and B6 are the transverse measuring points, and B5 and B7 are the longitudinal measuring points. The figure shows that the deformation at each position of the foundation is linear, which conforms to the pseudodynamic experimental hypothesis of single degree of freedom. The experimental and simulated deformation curves of the foundation are basically the same under transverse loading. The deformation of the upper part of the column in case 1 and 5 is larger than that in other cases. This phenomenon may be due to the decrease in rigidity caused by the separate pouring of the section. The loading position of the actuator under longitudinal loading is far from the displacement measurement position. The deformation along the height of the foundation is linear after applying seismic action, and the test deformation curve is smoother. The upper part is free in the numerical simulation, and the stiffness ratio is the main factor of deformation. The constraint of the one- and twostory platforms induces the deformation curve on the break point, and the simulation curve shows that the spring deformation is large.

4.2.5. Spring Deformation. The largest difference between spring and rigid common foundations lies in the spring isolation device that separates the column from the top deck, which will inevitably lead to different displacements of columns in frame foundation under horizontal earthquake action. Figure 15 is a comparison of the top displacement of each column and that of the top deck under the action of artificial synthetic wave, typical record Imperial Valley, and Alaska which are 7-degree fortification earthquakes under lateral loading. The first half is the experimental results, and the second half is the simulation results. The displacement connection at the top of the column to the spring isolator at the top of the base $\mathrm{C} 2 / \mathrm{C} 3 / \mathrm{C} 4 / \mathrm{C} 5 / \mathrm{C} 6$ column has large stiffness; therefore, the deformation of the spring is small, which shows the large displacement of the column. The maximum displacement of the top of the column appears in 


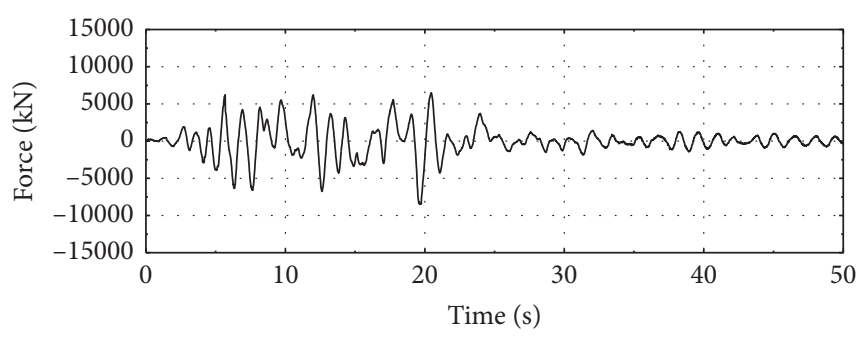

(a)

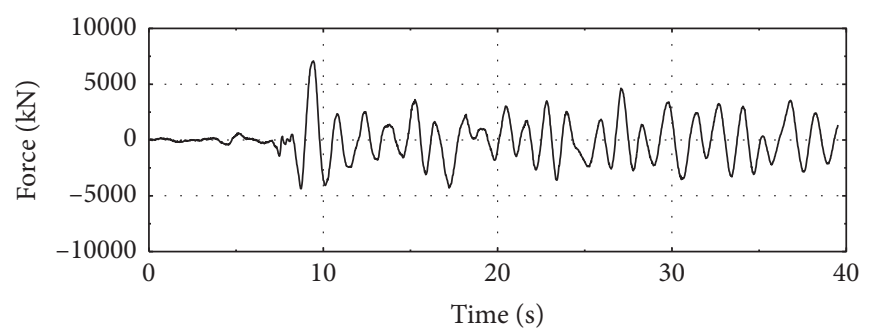

(c)

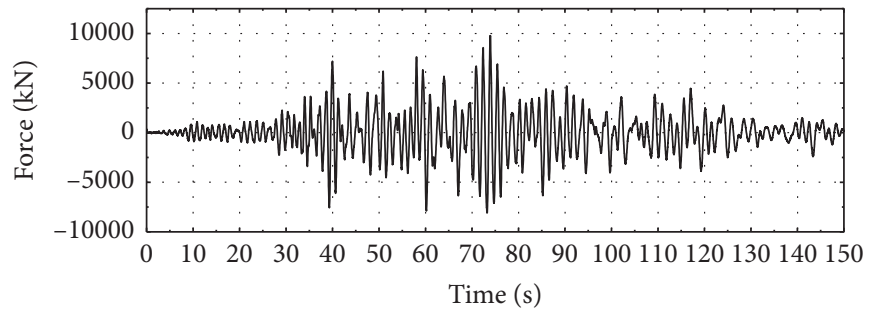

(e)

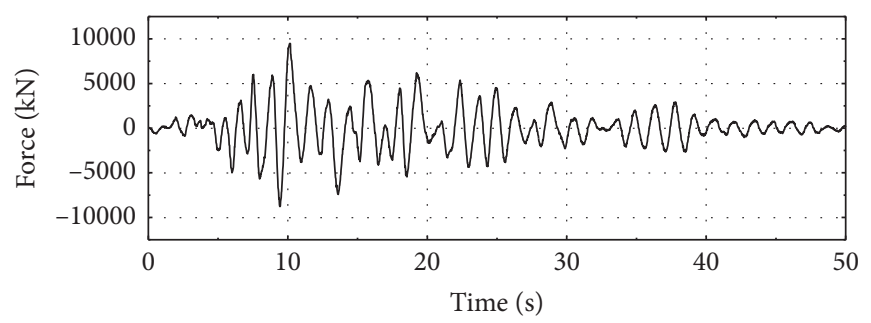

(b)

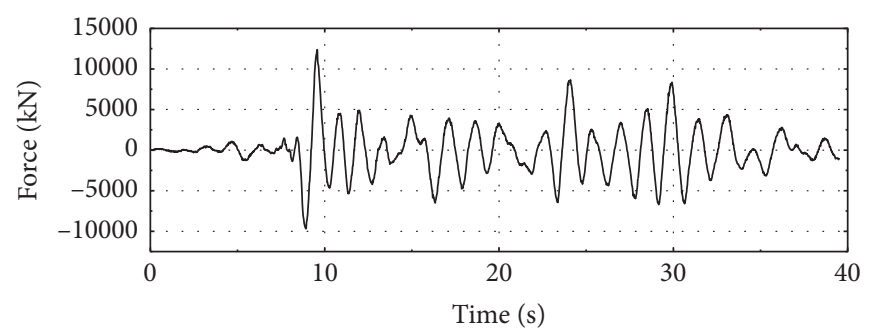

(d)

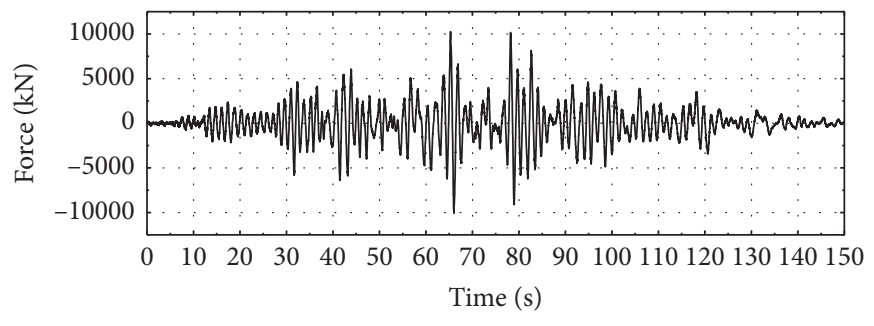

(f)

Figure 12: Force seismic response time-history curves. (a) Artificial synthetic-condition 1-transverse. (b) Artificial synthetic-condition 2longitudinal. (c) Imperial Valley-condition 3-transverse. (d) Imperial Valley-condition 4-longitudinal. (e) Alaska-condition 5-transverse. (f) Alaska-condition 6-longitudinal.

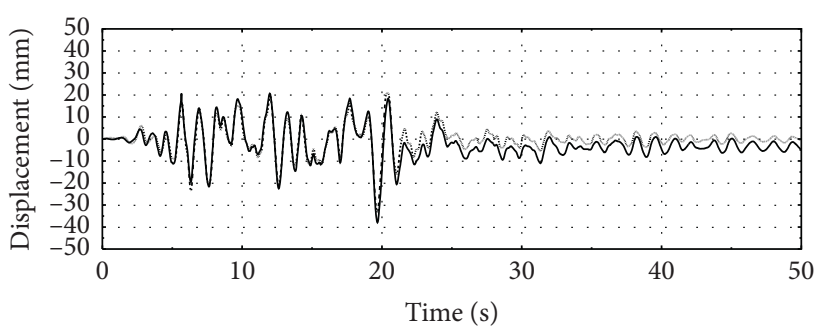

- Test

...- Simulation

(a)

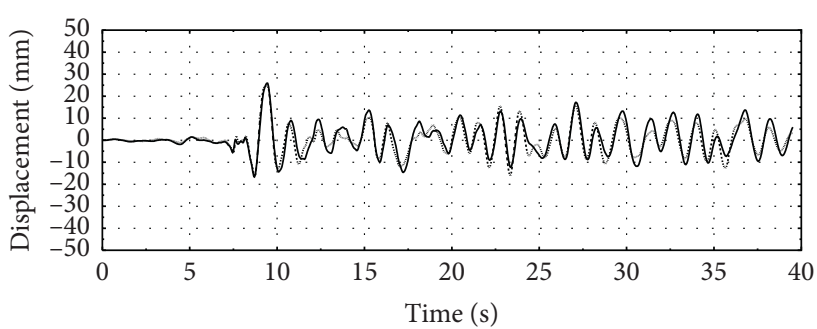

- Test

...- Simulation

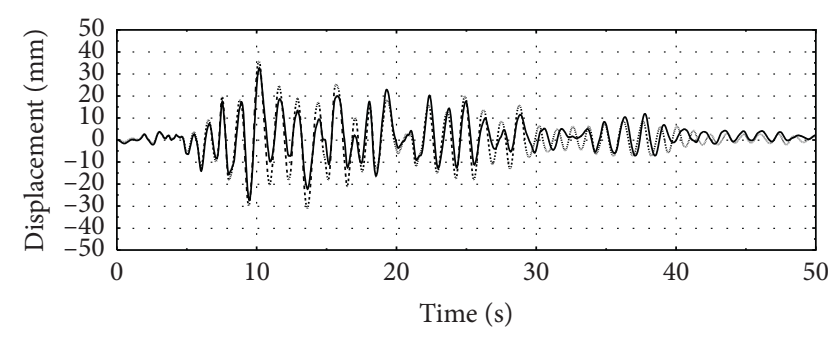

- Test

-. - Simulation

(b)

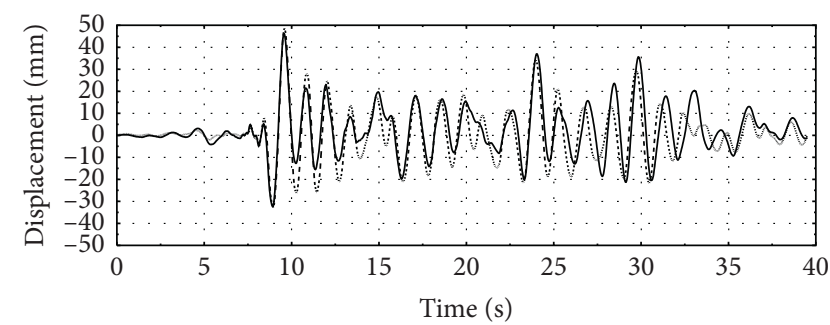

— Test

... Simulation

(c)

FIGURE 13: Continued. 


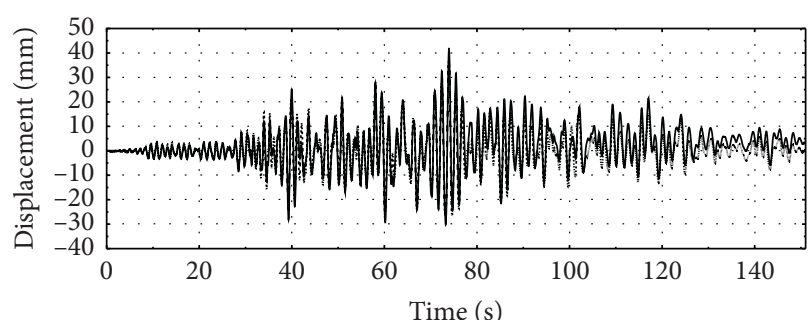

- Test
- Simulation

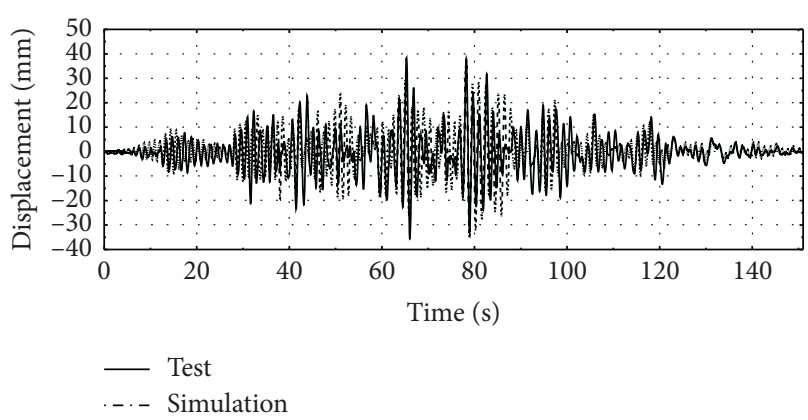

(f)

FIGURE 13: Displacement seismic response contrast between experiments and simulations. (a) Artificial synthetic-condition 1-transverse.

(b) Artificial synthetic-condition 2-longitudinal. (c) Imperial Valley-condition 3-transverse. (d) Imperial Valley-condition 4-longitudinal.

(e) Alaska-condition 5-transverse. (f) Alaska-condition 6-longitudinal.

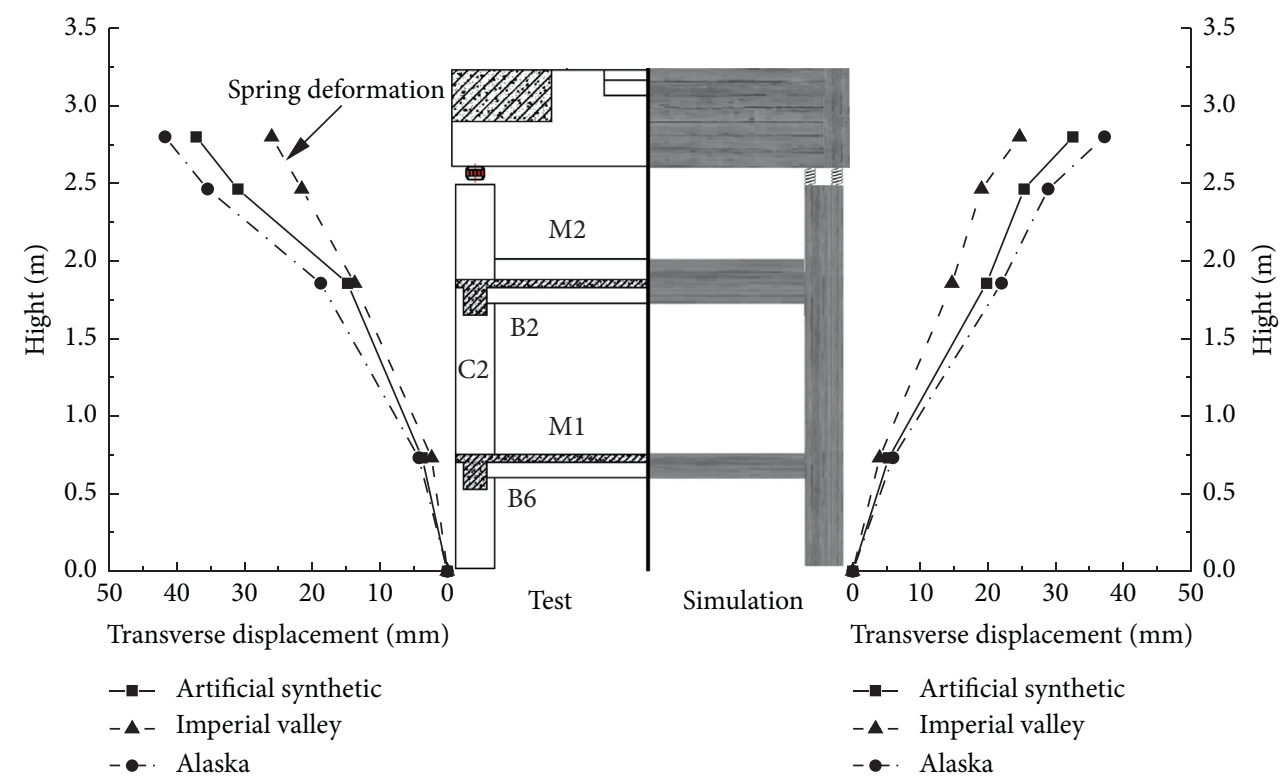

(a)

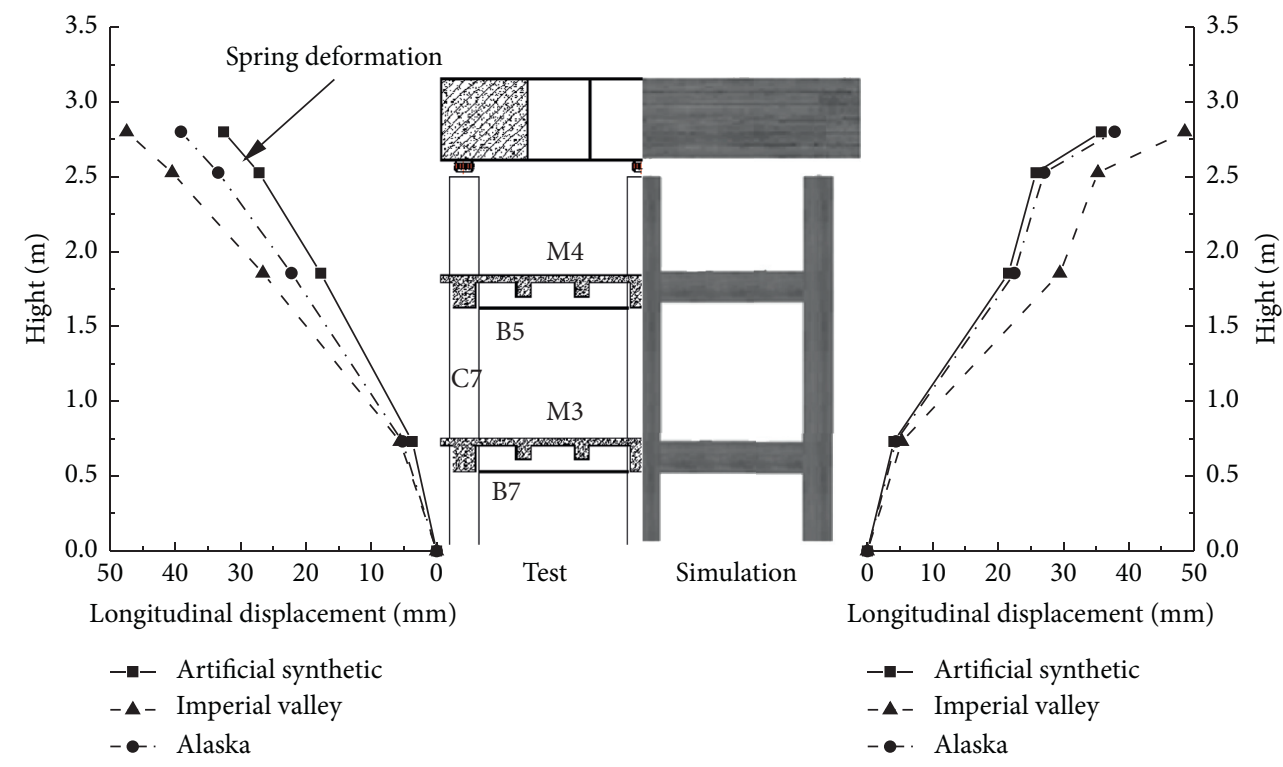

(b)

FIGURE 14: Displacement response contrast of different location. (a) Transverse loading. (b) Longitudinal loading. 


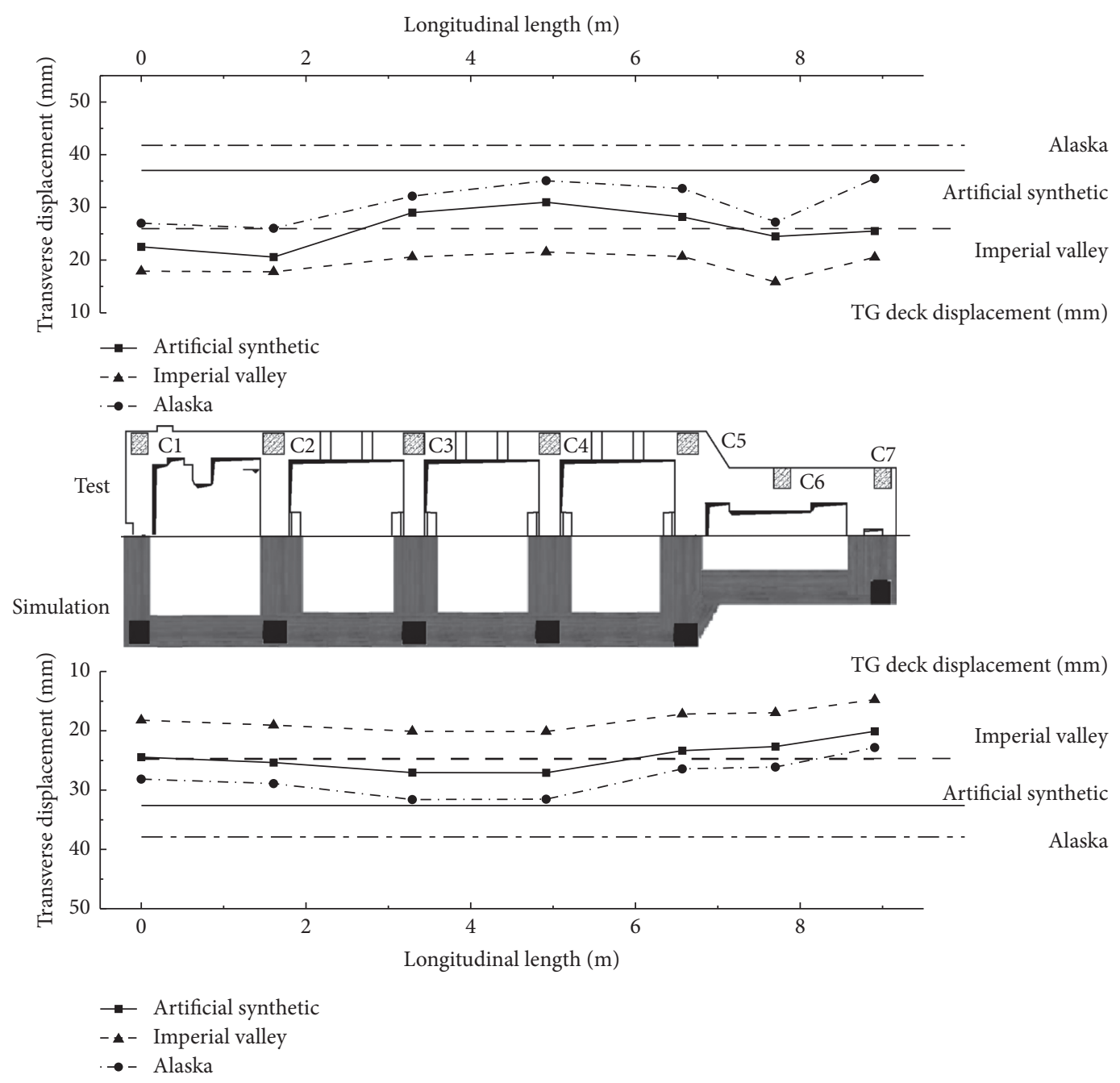

FIGURE 15: Displacement seismic response contrast of TG deck and column top.

C3 and C4 between the two low pressure cylinders in each condition. This phenomenon is due to the absence of other connections between the column and the entire structure except through the spring vibration isolator and the top deck, and the stiffness of the column is lower than that of other columns. Under the experimental conditions, the displacement of C7 column at the end of the high-pressure cylinder of the foundation is large, and the breaking point of the connecting line appears at C6. This situation is absent in the simulation possibly because the rigid center of the foundation platform does not coincide with the center of mass, and the longitudinal dimension is large. Moreover, the foundation demonstrates a small amount of torsion under lateral loading.

Table 7 shows the comparison between the maximum displacement of the top deck and that of the spring obtained by the test and simulation under various conditions. The dimensions of C3 and C4 columns are the same, and the horizontal stiffness of the top spring isolator is similar. The spring deformation should be equal regardless of pseudodynamic experiment of the top deck loading or the numerical simulation of the bottom loading of the column. The data in Table 7 only prove this point. The proportion of the spring deformation at the top of C3 and C4 is completely equal when the vertical loading is applied. The foundation model is slightly twisted when the vertical loading is applied, and the two are still remarkably close. The top displacement of the column from the spring deformation is different because the stiffness of each column and the corresponding spring isolator is different. However, the spring deformation accounts for approximately $20 \%$ of the displacement ratio of the platform plate, and some deformations exceed $40 \%$. Deformation values are distributed inversely according to the stiffness of columns and springs. The top displacement of columns with small and large stiffness is respectively large and small. The existence of spring vibration isolation device redistributes the seismic action of columns, induces uniform force of columns, gives full play to the resistance of each column, and improves the seismic performance of the foundation.

4.2.6. Comparison of Deck Displacements. Spring vibration isolation is an important part of the foundation structure. 


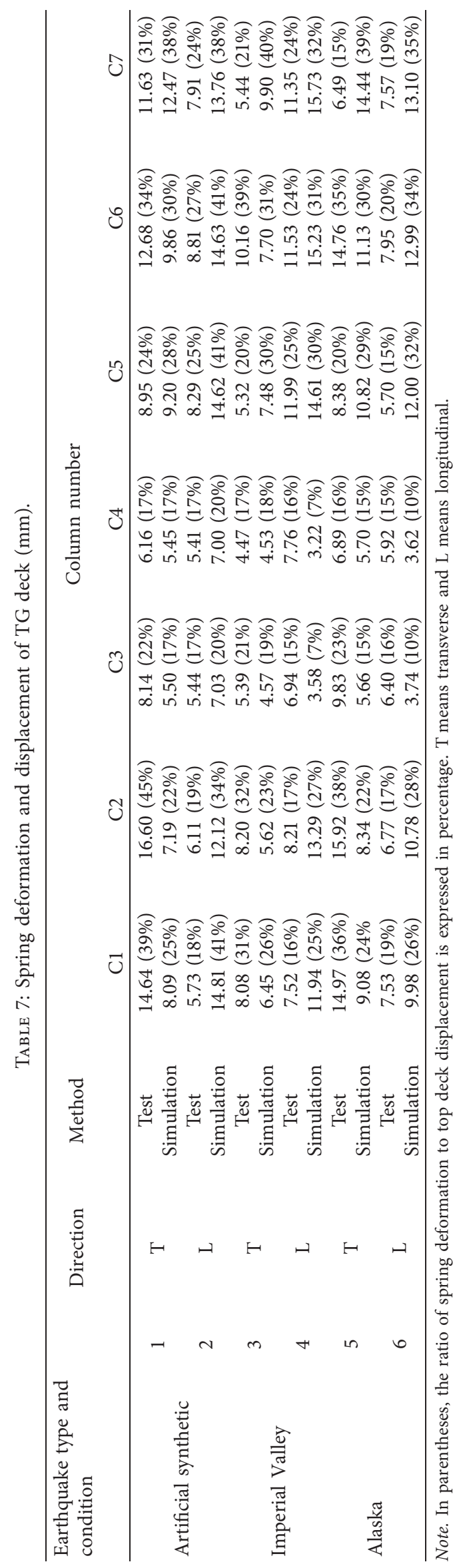


TABLE 8: Deck displacements before and after isolation ( $\mathrm{mm}$ ).

\begin{tabular}{lccc}
\hline Earthquake type & Number & After isolation & $\begin{array}{c}\text { Before } \\
\text { isolation }\end{array}$ \\
\hline \multirow{2}{*}{ Artificial synthetic Condition 1 } & 32.55 & 5.52 \\
& Condition 2 & 35.78 & 5.77 \\
\hline \multirow{2}{*}{ Imperial Valley } & Condition 3 & 24.67 & 4.21 \\
& Condition 4 & 48.59 & 8.22 \\
\hline \multirow{2}{*}{ Alaska } & Condition 5 & 37.25 & 5.03 \\
& Condition 6 & 37.84 & 4.75 \\
\hline
\end{tabular}

Maintaining the numerical model, only the spring isolators are removed, and the concrete frame beams and columns are fixed. The seismic response of the foundation slab is studied under the same conditions. Table 8 shows the comparison between the maximum displacement of the TG deck before and after isolation using spring isolators. The maximum displacement of the TG deck before isolation is less than that after isolation. Although the spring isolator can help the natural frequency of the foundation structure in avoiding the vibration frequency of the machine, because of its small horizontal stiffness, the seismic response of the structure is larger under horizontal earthquakes.

\section{Conclusions}

A 1:8 scale spring vibration isolation foundation of a nuclear power conventional island TG unit, including selfvibration characteristic test, pseudodynamic seismic experiments, and finite element simulation, is studied comprehensively in this paper. The results are transformed to prototype according to the similarity principle, and the comparative analysis of the test and simulation is conducted. The main conclusions are as follows:

(1) The first and second modes of the foundation are transverse and longitudinal translations with corresponding frequencies of 0.92 and $1.01 \mathrm{~s}$. The results of the SeismoStruct model established in this paper are the same as those of the test. The first and second frequencies are 1.06 and $1.12 \mathrm{~s}$, respectively. The overall model is closer to the test results. The results of natural vibration characteristics show that the natural frequency of spring vibration isolation foundation is low, and the vertical natural frequency is far away from the unit operating disturbance frequency $(25 \mathrm{~Hz})$.

(2) In the pseudodynamic test, the maximum responses of acceleration, velocity, displacement, and restoring force of turbine foundation plate under 7-degree fortification earthquake are $0.91 \mathrm{~m} / \mathrm{s}^{2}, 0.19 \mathrm{~m} / \mathrm{s}$, $47.42 \mathrm{~mm}$, and $12367 \mathrm{kN}$, respectively; in numerical simulation, the maximum responses of acceleration, velocity, displacement, and restoring force of turbine foundation plate under 7-degree fortification earthquake are $0.93 \mathrm{~m} / \mathrm{s}^{2}, 0.19 \mathrm{~m} / \mathrm{s}, 48.59 \mathrm{~mm}$, and $14444 \mathrm{kN}$, respectively.

(3) Under the action of earthquake, the acceleration of the spring vibration isolation base plate is not amplified, and the device can protect the steam turbine to reduce the impact of acceleration during earthquakes.

(4) Vibration isolation spring is crucial in resisting earthquakes. The vibration isolation spring separates the column and platform, and the displacement of the top of the column is no longer equal. The horizontal seismic force on the entire foundation is adjusted by the spring vibration isolation device and redistributed to each column to give full play to the seismic capacity of each column.

(5) Comparing the results with physical modelling and the numerical simulation, the foundation is simulated by the finite element method using SeismoStruct software. The error of natural vibration characteristic is approximately $15 \%$. The maximum error of seismic response is approximately $10 \%$, the trend of displacement seismic response curve is the same, and the magnitude is close. The approximation degree of the deformation curve at each position of the foundation is relatively high. The distribution of spring deformation is consistent, and the proportion of spring deformation to TG deck displacement is close. From the research object of this paper, the simulation effect is satisfactory and can meet the needs of the project.

(6) The comparison results of the maximum displacement of the TG deck before isolation and after isolation reveal that the maximum displacement of the TG deck after isolation is approximately six times that of that before isolation based on the seismic test.

(7) The result indicates that the foundation design meets the standard of "Code for Seismic Design of Buildings" in China and achieves the goal of spring vibration isolation and seismic resistance. According to the requirements of the seismic code, 1.2 times of the maximum displacement of the foundation slab is less than $200 \mathrm{~mm}$.

(8) The test process and results show that the loading mode of the seismic test has some influence on the seismic response of the structure, which needs further study in the future. Numerical simulation should be conducted in the future to supplement the research on the seismic performance of such structures.

\section{Data Availability}

The data used to support the findings of this study are available from the corresponding author upon request.

\section{Conflicts of Interest}

The authors declare that there are no conflicts of interest regarding the publication of this paper. 


\section{Acknowledgments}

This work was supported by the Youth Talent Support Program of North China University of Technology. The authors deeply express sincere appreciation to them.

\section{References}

[1] World Nuclear Association, Nuclear Power in China [EB/OL], World Nuclear Association, London, UK, 2018, http://www. world-nuclear.org.

[2] H. C. H. Liu, Concrete Foundations for Turbine Generators: Analysis, Design, and Construction, American Society of Civil Engineers (ASCE), Reston, VA, USA, 2018.

[3] G. S. H. Luo, J. X. Fang, and J. Wang, "Aseismic performance of spring supported turbo-generator foundation," Engineering Journal of Wuhan University, vol. 42, no. S1, pp. 436-442, 2009.

[4] X. Y. Shao, J. Z. H. Zhou, and X. J. Yin, "Research of model test of spring vibration isolated turbo-generator foundation-Test of dynamic characters," Engineering Journal of Wuhan University, vol. 44, no. S1, pp. 364-368, 2011.

[5] T. Zhu and C. L. Chen, "Vibration isolation for frame foundation of a power machinery," Journal of Vibration and Shock, vol. 29, no. 02, pp. 121-124+225, 2010.

[6] Y. Q. Song, X. Q. Zhou, and J. J. Wu, "Selection and design of spring foundation of half speed turbine generator for ling'ao Phase II NPP," Nuclear Power Engineering, vol. 32, no. S2, pp. 34-37, 2011.

[7] X. Y. Shao, J. Z. H. Zhou, and X. J. Yin, "Research of model test of spring vibration isolated turbo-generator foundationPseudo-dynamic earthquake test," Engineering Journal of Wuhan University, vol. 44, no. S1, pp. 389-392, 2011.

[8] D. Q. Mei, W. He, and Z. C. H. Chen, "Research on model test of frame foundation model for steam turbine-generator set," Power Engineering, vol. 21, no. 6, pp. 1523-1527, 2001.

[9] Z. G. Wang, N. Sun, and X. B. Gao, "Modal analysis for a 1:10 model of turbine-dynamotor frame foundation," Earthquake Engineering and Engineering Vibration, vol. 25, no. 1, pp. 33-37, 2005.

[10] L. G. Kang, X. W. Li, and Y. L. Xie, "Experimental research and analysis on dynamic characters of turbine-generator unit frame foundation," Journal of Building Structures, vol. 29, no. S1, pp. 20-26, 2008

[11] B. Y. Zhang, Q. J. Li, and W. Wang, "Experiment study on dynamic characteristics of spring vibration isolating foundation for large turbine-generator set," Journal of Harbin Institute of Technology, vol. 47, no. 4, pp. 37-43, 2015.

[12] W. F. Li, X. J. Wang, and Q. Sun, "Design of a combined vibration test rig for shafting and spring vibration-isolated foundation of nuclear power half-speed unites," Journal of Chinese Society of Power Engineering, vol. 37, no. 11, pp. 890-894+944, 2017.

[13] W. Liu and M. Novak, "Dynamic behaviour of turbinegenerator-foundation systems," Earthquake Engineering \& Structural Dynamics, vol. 24, no. 3, pp. 339-360, 1995.

[14] V. Karayel, E. Yuksel, T. Gokce, and F. Sahin, "Uni-axial shaking table tests and validations of a seismic isolation system made of spring tube braces," Soil Dynamics and Earthquake Engineering, vol. 118, no. 3, pp. 35-46, 2019.

[15] M.-W. Hur and T.-W. Park, "Performance evaluation of seismic isolation system by installation location in lighthouse structures," Shock and Vibration, vol. 2018, Article ID 5751623, 13 pages, 2018.
[16] D. An, X. Sun, and T. J. Qu, "Modal analysis of experiment on model of spring vibration isolated turbine-generator foundation," Journal of North China University of Technology, vol. 24, no. 3, pp. 84-88, 2012.

[17] T. J. Qu, K. Xiang, and X. J. Yin, "Pseudo-dynamic test of the anti-seismic performance of turbine generator foundation," Earthquake Resistant Engineering and Retrofitting, vol. 35, no. 1, pp. 115-119, 2013.

[18] M. M. Zan and T. J. Qu, "Test of the vibration isolation efficiency of spring-supported turbo-generator foundation," Journal of North China University of Technology, vol. 27, no. 1, pp. 80-83, 2015.

[19] X. G. Chen and T. J. Qu, "Modal test on the model of a foundation for 1000MW turbo-unit," Journal of North China University of Technology, vol. 29, no. 5, pp. 129-134, 2017.

[20] D. An and T. J. Qu, "Seismic behavior of turbine-generator foundation under strong earthquake action in different directions," Advances in Civil Engineering, vol. 2018, Article ID 2506264, 10 pages, 2018.

[21] S. Mohurd and M. Aqsiq, "Code for Seismic Design of Buildings": GB50011-2010, China Architecture and Building Press, Beijing, China, 2016 edition, 2016.

[22] S. Kumar, Y. Itoh, K. Saizuka, and T. Usami, "Pseudodynamic testing of scaled models," Journal of Structural Engineering, vol. 123, no. 4, pp. 524-526, 1997.

[23] S. Abdullah and N. H. A. Hamid, "Modelling of turbinegenerator and foundation as single degree of freedom using ruaumoko programme," International Journal of Engineering \& Advanced Technology, vol. 07, no. 01, pp. 18-31, 2012.

[24] M. Menegotto and P. E. Pinto, "Method of analysis of cyclically loaded RC plane frames including changes in geometry and non-elastic behavior of elements under normal force and bending," Preliminary Report, IABSE, vol. 13, pp. 15-22, 1973.

[25] J. B. Mander, M. J. N. Priestley, and R. Park, "Theoretical stress-strain model for confined concrete," Journal of Structural Engineering, vol. 114, no. 8, pp. 1804-1826, 1988. 